\title{
Ursodeoxycholic acid: a systematic review on the chemical and biochemical properties, biosynthesis, sources and pharmacological activities
}

\author{
Marlin Megalestin Raunsai a,", Elfahmi b,c, Agus Chahyadic, Sony Suhandono ${ }^{\mathrm{d}}$, Tati \\ Kristiantie, Laode M.R. Al Muqarrabun ${ }^{c}$
}

aResearch Center for Chemistry, Indonesian Institute of Sciences (LIPI), Building 452, PUSPIPTEK, Serpong, Banten, Indonesia bSchool of Pharmacy, Bandung Institute of Technology, Bandung, Indonesia.

cUniversity Center of Excellence for Nutraceuticals, Bioscience and Biotechnology Research Center, Bandung Institute of Technology, Bandung, West Java, Indonesia

dSchool of Life Sciences and Technology, Bandung Institute of Technology, Bandung, Indonesia.

eInstitut Pendidikan Indonesia, Garut, West Java, Indonesia.

\section{ABSTRACT}

Ursodeoxycholic acid (UDCA), a secondary bile acid (BA), is an acidic steroid synthesized from cholesterol in hepatocytes. UDCA is widely used for the treatment of various diseases related to liver injury. The use of UDCA to treat non-liver diseases has also been developed recently, such as neurodegenerative diseases, cancer, and obesity. Due to the important role of UDCA on human health, numerous studies in understanding its chemical and pharmacological properties have been published. Literature sources were obtained from online databases such as Science Direct, Google Scholar, Scopus and PubMed using keywords relating to the purpose of study. Critical analysis and review were performed for all literature. UDCA is a steroid compound with pharmacological properties. Seventeen enzymes are involved in its biosynthesis, which has been proposed in four pathways: classic, alternative, the Yamazaki, and 25-hydroxylation pathways. UDCA can be isolated from bovine bile, bear bile or all Ursidae, human, rabbit, cow, rat, hamster, sheep, pig, and plant. UDCA has been used in the treatment of several diseases such as primary biliary cirrhosis, intrahepatic cholestasis of pregnancy, hepatolithiasis associated with Caroli syndrome gallstones, cystic fibrosis, hepatitis C virus, chronic heart failure, neurodegenerative diseases, and obesity, as well as in the prevention of cancer. UDCA has a wide range of pharmacological properties. Further investigations on its efficacy and safety on humans are required before it could be used for several indications. All genes which are responsible in UDCA biosynthesis have been elucidated. That said, further genetic engineering studies in order to find other prospective sources of UDCA could be a challenge for the future research.

\author{
Article history: \\ Received 04 Aug 2021 \\ Revised 19 Aug 2021 \\ Accepted 23 Aug 2021 \\ Available online 31 Aug 2021 \\ Keywords: \\ Bile acid \\ chenodeoxycholic acid \\ cholic acid \\ UDCA \\ biosynthesis
}

\section{Introduction}

Cholesterol is a steroid compound used as a precursor in the biosynthesis of several compounds such as steroid hormones and bile acids (BAs) which have pharmaceutical properties. The accumulation of these sterols in the human body tends to be a risk factor for a number of diseases (Norlin and Wikvall, 2007). BAs derived from cholesterol serves as a physiological agent which facilitates the absorption of cholesterol, dietary fat, and lipidsoluble vitamins in the small intestine and the secretion of cholesterol and other compounds via defecation, to induce a biliary lipid secretion and bile flow (Chiang, 1998). Secondary BAs, such as lithocholic acid (LCA), deoxycholic acid (DCA) and ursodeoxycholic acid (UDCA), are formed from primary BAs and are modified by intestinal bacteria (Goossens and Bailly, 2019; Hofmann and Hagey, 2014). Particularly for UDCA, human liver only synthesizes it in a very small quantity, which is about $3-4 \%$ of the BA pool (Goossens and Bailly, 2019). UDCA, 3 $\alpha, 7 \beta$-dihydroxy$5 \beta$-cholanic acid), is an acidic steroid that is synthesized from cholesterol in hepatocytes (Wang and Wu, 2017). Among all the BAs, only UDCA was approved by the US Food and Drug Administration (FDA) for the treatment of PBC (Šarenac and Mikov, 2017). UDCA is widely utilized in the treatment of various diseases related to liver injury. However, the use of UDCA as an ingredient to treat non-liver-related diseases, such as neurodegenerative diseases, cancer, and obesity, has also been developed recently. Due to the important role of UDCA on human health, a lot of studies designed to better understand all aspects of the compound have been published. This article aims to provide a comprehensive, critical review on UDCA, especially those related to the chemical and biochemical properties, biosynthetic pathway, sources, and pharmacological properties of the compound. 


\section{Methods}

This research was conducted in August 2020 - August 2021. All information in this report was obtained from several scientific online databases. A total of 69 research reports and review articles were sourced, compiled, and reviewed. The information sources consisted of 15 articles from ScienceDirect (key words: UDCA, ursodeoxycholic acid, bile acid biosynthesis, cyp7a1, sources of UDCA, clinical uses of UDCA, and UDCA cholestatic), 36 articles from PubMed (keywords: UDCA, ursodeoxycholic acid, bile acid biosynthesis, cyp7a1, UDCA for cholestatic, enzymes of UDCA biosynthesis, UDCA for liver diseases, uses of UDCA, apoptosis regulation of UDCA, mechanism action of UDCA, and chemical characteristic of UDCA, UDCA and cancer), four articles from Springer (keywords: bile acid biosynthesis, sources of UDCA, pharmacology of UDCA and sterols from microorganisms), 13 articles from Google Scholar (keywords: bile acid biosynthesis, ursodeoxycholic acid, UDCA for cholestatic, and sources of UDCA), and one article from Scopus (keyword: Sources of UDCA). All the publications were taken without any year limitation.

\section{Results and discussion}

A literature search using several keywords related to all aspects about UDCA, especially its biochemical properties, biosynthesis pathway, natural sources, and pharmacological properties, has been carried out. Critical analysis and comprehensive review have been done to all the literatures, with no literatures being excluded due to lack of quality. From the most popular scientific online databases explored, 69 literature sources were collected. The small number of reports from online search indicated that studies on UDCA are still scarce. However, these studies were able to inspire further research to better understand the properties of UDCA considering its importance in drug development.

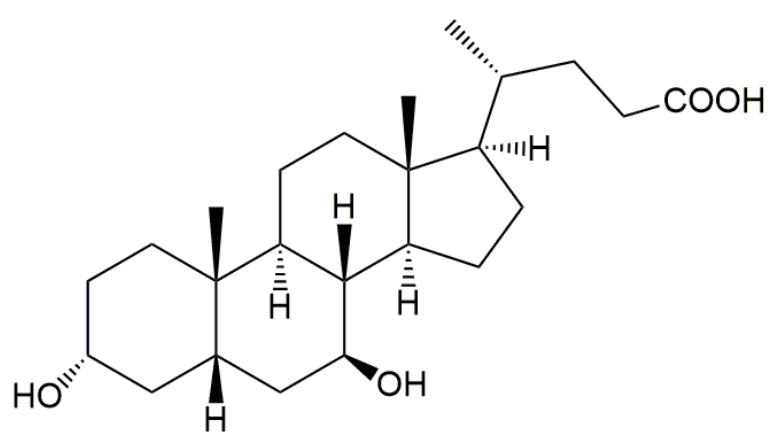

Fig.1. Chemical structure of UDCA

\subsection{Chemical and biochemical properties of UDCA}

BAs vary in orientation, position, and number in the steroid structures. The attached hydroxyl group could affect their adsorption, metabolism, distribution, solubility, as well as chemical and biochemical properties (Eggert et al., 2014; Poupon and Poupon, 1995; Tonin and Arends, 2018). Structurally, the BA steroid ring is exceptionally stable, rendering BAs difficult to metabolize (Lazaridis et al., 2001). Furthermore, the orientations ( $\alpha$ or $\beta$ ) of the hydroxyl group in the structure determines the hydrophilicity of the BAs (Chiang and Ferrell, 2020; Lazaridis et al., 2001). The hydrophobic $7 \alpha-\mathrm{OH}$ group in CDCA is converted into the $7 \beta-\mathrm{OH}$ group in UDCA, turning it hydrophilic (Fig. 1) (Ishizaki et al., 2005; Šarenac and Mikov, 2018). A higher level of hydrophilicity occurs when both hydroxyl groups of the steroid nucleus are located in $\alpha$ and $\beta$ orientations, compared to when the hydroxyl groups are both in $\alpha$ position (Ishizaki et al., 2005; Šarenac and Mikov, 2018). In addition, BAs are amphipathic in nature as they comprise both hydrophilic and hydrophobic surfaces in the structures, allowing lipophilic xenobiotics to be digested, emulsified, and absorbed after having a meal (Ishizaki et al., 2005; Šarenac and Mikov, 2018). Moreover, in terms of cytotoxicity, unconjugated BAs are found to be more toxic than the conjugated ones in general. For instance, UDCA, one of the $7 \beta$-hydroxy epimer of the conjugated primary BA CDCA, is less toxic than the other unconjugated BAs (Ishizaki et al., 2005; Noshiro et al., 1989).

\subsection{Biosynthesis of UDCA}

BAs in human liver are biosynthesized from cholesterol and the process involves 17 enzymes (Table 1) via several pathways. The enzymes involved in the biosynthesis of BAs are located in several cell compartments, such as mitochondria, peroxisomes, endoplasmic reticulum, and cytosol (Norlin and Wikvall, 2007; Schwarz et al., 1996). Chenodeoxycholic acid (CDCA) and cholic acid (CA) and, two primary BAs which are also synthesized from cholesterol, are conjugated with either glycine or taurine and are excreted with bile into the intestine (Ishizaki et al., 2005; Noshiro et al., 1989). Intestinal bacteria modify the side chains by deconjugation and dehydroxylation of CA and CDCA portions to form secondary BAs; deoxycholic acid, lithocholic acid, and also ursodeoxycholic (UDCA), albeit in a very small amount (Eggert et al., 2014). UDCA, in particular, can be synthesized from CA, which is the most abundant and inexpensive BA (Eggert et al., 2014). The modification of cholesterol to secondary BAs involves three main steps, which are 1) the addition of hydroxyl groups to specific positions on the sterol nucleus; 2) the saturation of the steroid nucleus and epimerization of the 3p-hydroxyl group, and 3) the side-chain oxidation and shortening by three carbon atoms (Vlahcevic et al., 1999).

Primary and secondary BAs that have been formed, in a process called enterohepatic circulation, can be reabsorbed into the bloodstream, back to the liver, and then secreted (Eggert et al., 2014). There are two driving forces in the enterohepatic circulation pattern. Firstly, approximately $95 \%$ of BAs are absorbed through the intestine and are returned to the liver; this happens in the terminal ileum. Secondly, bile salts are extracted by hepatocytes and present in low concentrations in the systemic circulation; this occurs in the liver (Poupon and Poupon, 1995). Ultimately, the biosynthetic pathway and the type of BAs synthesized can be different for each species (Chiang, 1998). Currently, there are four known main pathways of BA biosynthesis, including the classic, alternative, Yamasaki, and 25-hydroxylation pathways (Fig. 2) (Šarenac and Mikov, 2018; Vaz and Ferdinandusse, 2017). Each pathway will be discussed in the next parts of this report.

\subsubsection{The classic BA biosynthetic pathway}

The classic pathway in BA biosynthesis is also called the neutral pathway because BA precursors are used as neutral steroids in most of the pathway (Norlin and Wikvall, 2007). Cholesterol $7 \alpha$ hydroxylase (CYP7A1), a cytochrome P450 microsome enzyme, converts cholesterol to $7 \alpha$-hydroxycholesterol (Ferdinandusse and Houten, 2006). In the classic pathway, the steps that are involved include the modification of the sterol nucleus, the epimerization of the $3 \beta$-hydroxyl group, and the hydroxylation at the $7 \alpha$ and $12 \alpha$ positions which precedes the oxidative cleavage of the side chain (Chiang, 2004). Some other enzymes are also involved in this pathway, consisting of a cascade of 14 steps (Chiang, 2004). In physiological conditions, the classic pathway may be the main pathway, constituting about $90 \%$ and $75 \%$ in human and mice, respectively, in the total contribution (Šarenac and Mikov, 2017).

\subsubsection{The alternative (acidic) BA biosynthetic pathway}

The alternative pathway is called the acidic pathway because BA precursors for the pathway are carboxylic acids (Norlin and Wikvall, 2007). This pathway has the main function of removing cholesterol from the extrahepatic tissues (Norlin and Wikvall, 
2007). The alternative pathway contributes predominantly to patients with liver disease (Chiang, 2004).

In the alternative BA biosynthetic pathway, side chain modifications occur before the modification of the sterol nucleus (Vlahcevic et al., 1999). The biosynthesis is initiated by the conversion of cholesterol to 27-hydroxycholesterol and $3 \beta$-hydroxy5-cholestenoic acid by mitochondrial sterol 27-hydroxylase (CYP27) (Chiang, 1998). Sterol 27-hydroxylase forms 27hydroxycholesterol and hydroxylates cholesterol at carbons 24 and 25 (Ferdinandusse and Houten, 2006). These two sterols further undergo $7 \alpha$-hydroxylation to be converted into BAs (Ferdinandusse and Houten, 2006).

\subsubsection{The Yamasakhi BA biosynthesic pathway}

As in the alternative pathway, the Yamasaki pathway also results in C24 BAs and 3 $\beta$-hydroxy-5-cholenoic acid and is followed by structural modifications of the steroid ring (Šarenac and Mikov, 2018). In human, the Yamasaki pathway has a major product, chenodeoxycholic acid (CDCA), and may contributes to fetal development. However, this pathway contribution to BA pool is not clear (Vaz and Ferdinandusse, 2017).

\subsubsection{5-hydroxylation BA biosynthesic pathway}

BA biosynthesis via 25-hydroxylation pathway is initiated by CYP7B1 enzyme converting 25-hydroxycholesterol to $5 \beta$-cholesten$3 \alpha, 7 \alpha, 25$-triol which is then transformed into BAs in the liver (Chiang, 2004). The 25-hydroxylation pathway undergoes ring structure modifications without the need for 27-hydroxylation and subsequent peroxisome $\beta$-oxidation to obtain C24-carboxylic acid (Vaz and Ferdinandusse, 2017). The contribution of this pathway is minuscule to BAs synthesis in human (Chiang, 2004).

\subsection{Sources of UDCA}

UDCA can be obtained naturally from animals and plants (Table 2). While UDCA can be synthesized directly due to it being the primary BA in some animals, UDCA can also be synthesized naturally and chemically from its raw materials.

\subsubsection{Sources of UDCA from animals}

Animals, especially vertebrates, can produce UDCA from its precursors like CA and CDCA in varying proportions depending on the species. CA is known as the main precursor in UDCA synthesis because it is found in large amount in bovine bile compared to CDCA (Tonin and Arends, 2018).

All Ursidae can produce UDCA because it is their primary BA (Hagey et al., 1993). One of the reasons is the non-exposure of all BAs in Ursidae to bacterial enzymes, and this factor is not found in human (Hagey et al., 1993). This is one of the causes that UDCA is produced in an extremely small quantity in human. On the contrary, pork is widely used in the production of UDCA owing to its high level of hyocholic and hyodeoxycholic acids (Hagey et al., 1993).

The use of animals in UDCA production has its advantages and disadvantages. The advantages are that many animals can produce UDCA precursors and that UDCA is found as primary BAs in some animals. Nevertheless, several drawbacks related to the synthesis of UDCA are also existent, including problems related to the initial process of slaughtering particularly with bovine and weaknesses related to sanitation and the complexity of the synthesis process which requires a lot of money (Tonin and Arends, 2018). Furthermore, Feng et al. (2009) also found that there are concerns growing over the existence of wild bears due to the sale of their gall bladders offers ludicrous profit, especially in China and Hong Kong.

Table 1. Enzymes of BA synthesis

\begin{tabular}{|c|c|c|}
\hline Genes & Enzymes & References \\
\hline Cytochrome P450 Family 7 Subfamily A Member 1 (CYP7A1) & Cholesterol 7 $\alpha$ a-hydroxylase & $\begin{array}{l}\text { Noshiro et al. (1989); } \\
\text { Schwarz et al. (1996) }\end{array}$ \\
\hline Cytochrome P450 Family 46 Subfamily A Member 1 (CYP46A1) & Cholesterol 24-hydroxylase & Lund et al. (1999) \\
\hline Cholesterol 25-Hydroxylase $(\mathrm{CH} 25 \mathrm{H})$ & Sterol 25-hydroxylase & Shefer et al. (1976) \\
\hline Cytochrome P450 Family 27 Subfamily A Member 1 (CYP27A1) & Sterol 27-hydroxylase & $\begin{array}{l}\text { Björkhem et al. (1994); Reiss } \\
\text { et al. (1994) }\end{array}$ \\
\hline Cytochrome P450 Family 39 Subfamily A Member 1 (CYP39A1) & Oxysterol $7 \alpha$-hydroxylase & Li-Hawkins et al. (2000a) \\
\hline Cytochrome P450 Family 7 Subfamily B Member 1 (CYP7B1) & Oxysterol $7 \alpha$-hydroxylase & $\begin{array}{l}\text { Li-Hawkins et al. (2000a, } \\
\text { 2000b); Schwarz et al. (1997) }\end{array}$ \\
\hline $\begin{array}{l}\text { Hydroxy-Delta-5-Steroid Dehydrogenase, } 3 \text { Beta- And Steroid Delta- } \\
\text { Isomerase } 7 \text { (HSD3B7) }\end{array}$ & $\begin{array}{l}3 \beta \text {-hydroxy-A5-C27 steroid } \\
\text { oxidoreductase }\end{array}$ & $\begin{array}{l}\text { Buchmann et al. (1990); } \\
\text { Schwarz et al. (2000) }\end{array}$ \\
\hline Cytochrome P450 Family 8 Subfamily B Member 1 (CYP8B1) & Sterol $12 \alpha$-hydroxylase & $\begin{array}{l}\text { Andersson et al. (1989); Usui } \\
\text { et al. (1990) }\end{array}$ \\
\hline Aldo-Keto Reductase Family 1 Member D1 (AKR1D1) & A4-3-Oxosteroid $5 \beta$-reductase & $\begin{array}{l}\text { Clayton et al. (1996); } \\
\text { Pawlowski et al. (1991); } \\
\text { Setchell et al. (1988) }\end{array}$ \\
\hline Aldo-Keto Reductase Family 1 Member C4 (AKR1C4) & $3 \alpha$-Hydroxysteroid dehydrogenase & \\
\hline Cytochrome P450 Family 27 Subfamily A Member 1 (CYP27A1) & Sterol 27-hydroxylase & $\begin{array}{l}\text { Björkhem et al. (1994); Reiss } \\
\text { et al. (1994) }\end{array}$ \\
\hline Solute Carrier Family 27 Member 5 (BACS/SLC27A5) & Bile acid CoA ligase & Prydz et al. (1988) \\
\hline Alpha-Methylacyl-CoA Racemase (AMACR) & $\begin{array}{l}\text { 2-Methylacyl-CoA racemase / } \alpha \text { - } \\
\text { Methylacyl-CoA racemase }\end{array}$ & Schmitz et al. (1994) \\
\hline Acyl-CoA Oxidase 2 (ACOX2) & $\begin{array}{l}\text { Branched-chain acyl-CoA oxidase / } \\
\text { Acyl-CoA oxidase } 2\end{array}$ & van Veldhoven et al. (1991) \\
\hline $\begin{array}{l}\text { D-Box Binding PAR BZIP Transcription Factor (DBP) /Hydroxysteroid } \\
\text { 17-Beta Dehydrogenase } 4 \text { (HSD17B4) }\end{array}$ & D-bifunctional protein hydratase & Suzuki et al. (1997) \\
\hline Sterol Carrier Protein 2 (SCP2) /SCPx & Peroxisomal thiolase 2 & Antonenkov et al. (1999) \\
\hline Bile Acid-CoA:Amino Acid N-Acyltransferase (BAAT) & $\begin{array}{l}\text { Bile acid CoA: amino acid } \mathrm{N}- \\
\text { acyltransferase }\end{array}$ & Kase and Björkhem, (1989) \\
\hline
\end{tabular}




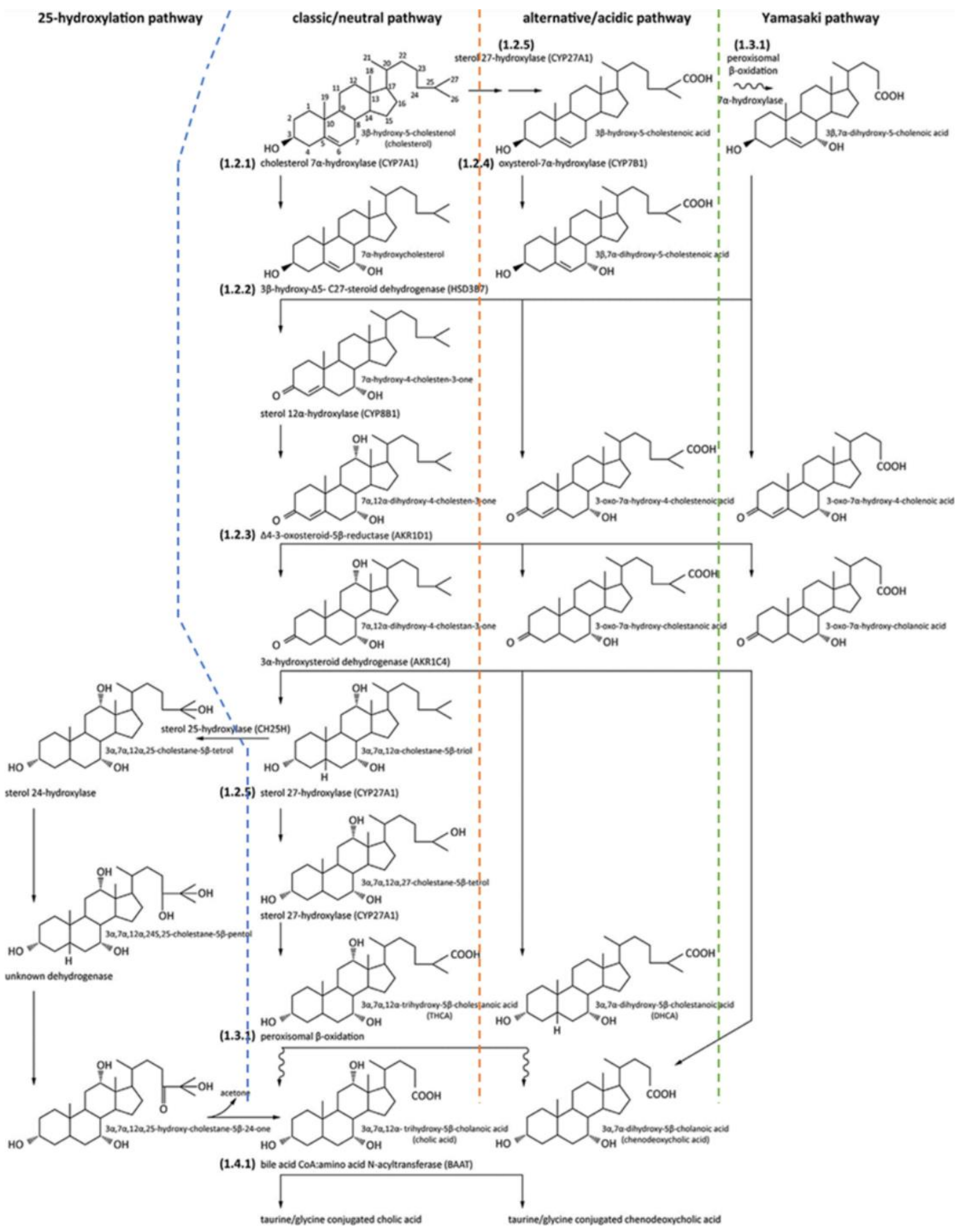

Fig. 2. Biosynthesis of UDCA precursors 


\subsubsection{Sources of UDCA from plants}

So far, no synthesis route has been discovered in UDCA production using precursors from plants. However, in a recent study, Wang et al. (2020) succeeded in using plant bisnoralcohol (Fig. 3) obtained from side-chain degradation of the phytosterols with the help of bacteria to produce UDCA. They claim that the UDCA synthesis route from this plant-sourced bisnoralcohol is more efficient and economical because it can be produced on a large scale. Moreover, the use of eukaryotic microorganisms, like yeast and algae, in UDCA production is also being considered but is still in the early stages of investigation (Tonin and Arends, 2018). Ultimately, chemical and enzymatic manipulations can be developed from microalgae cultivation to provide new varieties in the sterol structures (Volkman, 2003).

\subsection{Pharmacological activities of UDCA}

UDCA has been used in ancient Chinese medicine 'Yutan', which is derived from the dry bile of adult bears for the treatment of hepatobiliary disorders (Ishizaki et al., 2005; Noshiro et al., 1989). Further development of UDCA from successful studies on its pharmacological activities has brought this compound to the FDA approval specifically for its treatment of primary biliary cirrhosis (PBC) and for its utilization for various liver diseases in general. The main use of UDCA in therapeutic purposes is for the patient with PBC. The studies also revealed that UDCA showed exhibited other biological activities on non-liver diseases such as cancer, chronic heart failure, degenerative diseases, microbial infection, and obesity. The pharmacological properties of UDCA are summarized in Table 3 . In addition, UDCA has been clinically used in the pharmaceutical industry and is known for its antiinflammatory and immunomodulating actions. Recently, several researchers recommended UDCA to be added to the current treatment protocols of COVID-19 (Abdulrab et al., 2020).

\subsubsection{Liver disease}

The application of UDCA has been shown to improve hepatic histology and reduce serum bilirubin level as important analytic markers in PBC (Šarenac and Mikov, 2018), including defective bile secretion, inflammation, cholangiocyte senescence and apoptosis, and innate and adaptive immune responses (Corpechot et al., 2020). In general, major mechanisms of action of UDCA in cholestatic diseases involve the stimulation of cholangiocellular, the stimulation of hepatocellular secretion, secretion, antiapoptotic effects, and the reduction in bile toxicity (Beuers et al., 2015). A double-blind clinical study has been conducted in 12 centers involving 55 patients receiving daily dose of UDCA of $15 \mathrm{mg} / \mathrm{kg}$ bodyweight for the duration of one a year. The results demonstrated that UDCA was able to improve the biochemical and clinical parameters of the patients (Colombo et al., 1996). Furthermore, a recent clinical study which involved a larger number of participants (780 patients from 16 centers from 9 countries) to investigate the preventive capability of UDCA against the recurring of PBC after liver transplantation has been reported. The study revealed the reduction in the risk of $\mathrm{PBC}$ recurrence, graft lost, and mortality of patients after liver transplantation, owing to the use of UDCA in the post-surgery treatment (Corpechot et al., 2020).

\subsubsection{Cancer}

Several studies investigating the biological activities of UDCA for cancer diseases have been reported. These studies, ranging from preclinical and clinical trials, were emphasizing on the utilization of UDCA in the cancer prevention and treatment. The preventive effect and the treatment of UDCA against cancer diseases may happen via several possible mechanisms. In vitro studies using several cell lines such us melanoma, colon cancer, and gastric cancer showed that UDCA could inhibit apoptosis in some situations, while also being able to induce apoptosis in other conditions. A study by Chen et al. (2019) showed the proliferation of human M14 melanoma cells can be suppressed by UDCA via a mitochondria-associated pathway triggered by ROS. In a pancreatic cancer study, UDCA depressed the stem cell formation of HPAC and Capan-1 cells (Kim et al., 2017). Contrariwise, UDCA can also inhibit apoptosis induced by deoxycholic acid (DCA) in HCT116 human colon cancer cell line, through modulation of EGFR/Raf1/ERK signaling (Shah et al., 2005). In addition, in vivo investigations using animal models as well as clinical studies on human subjects showed that UDCA, with and without combination with other drugs, exhibited cytotoxicity against those cancer cell lines and could reduce cancer risk in human (Kim et al., 2018; Kohno et al., 2007; Lee et al., 2020; Park et al., 2008).

Table 2. Sources of UDCA

\begin{tabular}{|c|c|c|}
\hline Sources & Precursors & References \\
\hline Bovine bile & CA and CDCA & Tonin and Arends (2018) \\
\hline All Ursidae & $\begin{array}{l}\text { The average content of UDCA is } 1-39 \% \text { of } \\
\text { biliary BAs depending on the species }\end{array}$ & Feng et al. (2009); Hagey et al. (1993) \\
\hline $\begin{array}{l}\text { Human, rabbit, cow, rat, hamster, } \\
\text { sheep, pig, goose, birds, fishes, ox }\end{array}$ & $\begin{array}{l}\text { UCDA, CA, CDCA, hyodeoxycholic acid } \\
\text { (HDCA) }\end{array}$ & $\begin{array}{l}\text { Kuhajda et al. (2006); Russell (2003); } \\
\text { Elfahmi and Chahyadi (2020) }\end{array}$ \\
\hline
\end{tabular}

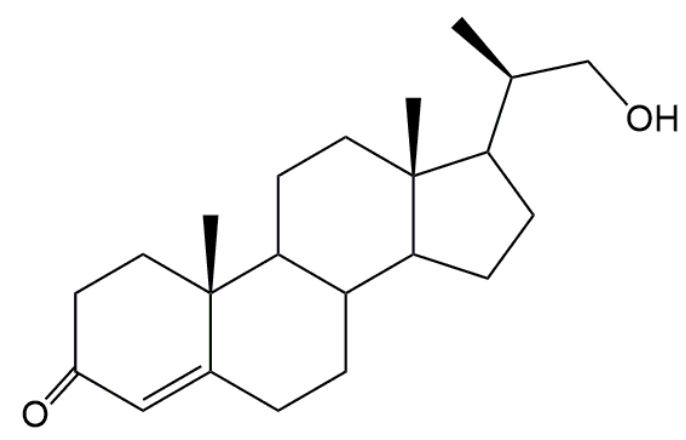

Fig.3. Chemical structure of bisnoralcohol 


\subsubsection{Chronic heart failure}

The potential prospect of the use of UDCA as a drug for chronic heart diseases have been revealed from several studies. Numerous reports signify in vitro, in vivo, and clinical studies of the pharmacological activities of UDCA against heart diseases. In vitro studies in rat model organs showed that UDCA has the potential to be developed as a drug for chronic diseases. The mechanisms of UDCA were revealed through the induction of cyclic adenosine monophosphate (cAMP), reduction of lactate dehydrogenase (LDH) release and the enhancement of the cardiac contractile function (Ibrahim et al., 2018; Lee et al., 1999); the improvement in calcium level intracellularly and the activation of ATP-sensitive calcium (KATP) channels (Miragoli et al., 2011); and downregulation of caspase-9 and reactive oxygen species (ROS) regarding Hypoxia (Hanafi et al., 2017). Other in vivo studies on mouse models of diabetic atherosclerosis revealed that UDCA could reduce endoplasmic reticulum stress as one of indicators for antiatherogenic activity (Chung et al., 2016). Additionally, the clinical studies on patients with coronary heart diseases found that UDCA was able to improve endothelium and NO-independent vasodilatation which maintain the arterial flow of the patients (Sinisalo et al., 1999).

\subsubsection{Neuro-degenerative diseases}

Lots of research of pharmacological properties of UDCA and its conjugate with taurine on neurogenerative diseases have been also reported. A study on Huntington's disease (HD) conducted by Keene et al., (2001) exhibited that depletion of 3-nitropropionic acid (3NP)-mediated striatal nerve cell death in cell culture was affected by TUDCA treatment. HD is a disease that is associated with disruption of mitochondrial energy metabolism, such as Parkinson's disease, Alzheimer's disease, Freidreich's ataxia or some related neurodegenerative diseases, so it is very likely that treatment with TUDCA is predicted to be applied to these diseases (Keene et al., 2001). In the in vitro study using cell line SH-SY5Y, UDCA demonstrated the capability of protecting the human dopaminergic neuronal against the cytotoxicity induced by sodium nitroprusside in the cells. That said, along with its conjugates and other derivatives, UDCA has shown to be a promising candidate to be developed as a drug for the therapy of neurodegenerative diseases in the future.

Table 3. Pharmacological uses of UDCA

\begin{tabular}{|c|c|c|}
\hline Pharmacological uses & Clinical/laboratory features & References \\
\hline Primary Biliary Cholangitis (PBC) & UDCA decreased risk of graft loss, disease recurrence, and death. & Corpechot et al. (2020) \\
\hline Intrahepatic cholestasis of pregnancy (ICP) & $\begin{array}{l}\text { UDCA improved the biochemical and clinical parameters of } \\
\text { cholestasis and safe for the fetus. }\end{array}$ & Mazzella et al. (2001) \\
\hline $\begin{array}{l}\text { Hepatolithiasis associated with Caroli } \\
\text { syndrome }\end{array}$ & $\begin{array}{l}\text { UDCA caused sustained clinical remission, return to normal liver } \\
\text { function, and dissolution of intrahepatic stones on ultrasound in all } \\
\text { patients. }\end{array}$ & Ros et al. (1993) \\
\hline Cystic fibrosis & $\begin{array}{l}\text { UDCA increased biochemical indications of cholestasis, nutritional } \\
\text { status, and general condition. }\end{array}$ & Colombo et al. (1996) \\
\hline Prevention of cancer & $\begin{array}{l}\text { UDCA not only protected cells from damages and supressed apoptosis } \\
\text { but also can induce apoptosis. }\end{array}$ & $\begin{array}{l}\text { Chen et al. (2019); Kim et al. } \\
\text { (2017); Shah et al. (2005) }\end{array}$ \\
\hline Autoimmune hepatitis & $\begin{array}{l}\text { UDCA may have depressed T-cell activity and instigated a decline of } \\
\text { HLA class I antigens against hepatocytes together with prednisolone } \\
\text { in a synergistic manner. }\end{array}$ & Mima et al. (1994) \\
\hline $\begin{array}{l}\text { Hydroxy-Delta-5-Steroid Dehydrogenase, } 3 \\
\text { Beta- And Steroid Delta-Isomerase } 7 \\
\text { (HSD3B7) }\end{array}$ & $\begin{array}{l}\text { The use of UDCA indicated a degradation in serum alanine transferase } \\
\text { (ALT) and serum BA hydrophobicity index. }\end{array}$ & Takano et al. (1994) \\
\hline Chronic heart failure & $\begin{array}{l}\text { In vitro studies mechanisms of UDCA were referred through the } \\
\text { induction cAMP, reduction of LDH release and the enhancement of } \\
\text { the cardiac contractile function; the improvement in calcium level } \\
\text { intracellularly and the activation of KATP channels; and the inhibition } \\
\text { of the expression of hypoxia factor } 1 \text { alpha and downregulation of } \\
\text { caspase-9 and ROS. UDCA could reduce endoplasmic reticulum stress } \\
\text { and improve endothelium and NO-independent vasodilatation } \\
\text { regarding in vivo studies. }\end{array}$ & $\begin{array}{l}\text { Chung et al. (2016); Hanafi et } \\
\text { al. (2017); Ibrahim et al. } \\
\text { (2018); Lee et al. (1999); } \\
\text { Miragoli et al. (2011); } \\
\text { Sinisalo et al. (1999) }\end{array}$ \\
\hline Neurodegenerative diseases & $\begin{array}{l}\text { T/UDCA serves as a neuroprotectant against acute injuries and could } \\
\text { inhibit apoptosis by interfering early on with the mitochondrial } \\
\text { pathway of cell death and associated processes. }\end{array}$ & $\begin{array}{l}\text { Chun and Low (2012); Keene } \\
\text { et al. (2001) }\end{array}$ \\
\hline Obesity & $\begin{array}{l}\text { UDCA remarkably diminished lipid droplets, enhanced mitochondrial } \\
\text { function, decreased free fatty acids (FFA) and triglycerides (TG), and } \\
\text { increased white adipose tissue browning in ob/ob mice. }\end{array}$ & Chen et al. (2019) \\
\hline Antibacterial activity & $\begin{array}{l}\text { UDCA affected the composition of the intestinal microflora and } \\
\text { preserved the sterility of the biliary tract. }\end{array}$ & Šarenac and Mikov (2018) \\
\hline Hepatoprotective effect & $\begin{array}{l}\text { TUDCA dose-dependently protected TCDCA-induced GPT release in } \\
\text { hepatocytes }\end{array}$ & Ishizaki et al. (2005) \\
\hline Nonalcoholic fatty liver disease & Inhibiting apoptosis and improving autophagy by activating AMPK & Wu et al. (2020) \\
\hline
\end{tabular}

\subsubsection{Diabetes and obesity}

In vivo study on obese mice models, UDCA exhibited a potential anti-obesity property. This effect was indicated by several parameters related to obesity-related diseases such as decreasing the level of lipid, fatty acids, and triglycerides; improving the function of mitochondria; and enhancing adipose tissue browning of animal models. UDCA also showed the modulation in glucose and lipid biosynthesis, anti-inflammatory property, macrophage differentiation, and angiogenesis. All parameters related for obesity suggested the potential of UDCA to be developed as a drug to treat obesity. Furthermore, as obesity could lead to other metabolic diseases such as diabetes (Chen et al., 2019), it is also promising that the conjugate of UDCA, tauroursodeoxycholic acid, protects podocytes by inhibiting autophagy damage in diabetes (Fang et al., 2013).

\section{Conclusion}

In this review, the chemical and biochemical properties, biosynthesis, sources and pharmacological activities have been described. UDCA is a hydrophilic and non-toxic secondary BA. The elucidation of all enzymes in every step of UDCA biosynthesis has provided adequate insights for further research. Ultimately, the availability of their gene sequences which code the enzymes could 
be capitalized in for the genetic engineering of these genes to produce UDCA and its derivatives with synthetic biology. Up until now, the sources of UDCA and its derivatives are mostly from animals with low concentration. The efforts in finding other sources of UDCA such as plants or engineered microorganisms are of essence. Ursodeoxycholic acid (UDCA) has been proven as a drug for liver-related diseases, especially for primary biliary cholangitis (PBC). Numerous studies have been reported to support this therapeutic use. In addition to PBC, UDCA also showed the pharmacological properties in the prevention and treatment of other liver diseases, such as hepatolithiasis, cystic fibrosis autoimmune hepatitis, and hepatitis virus infection. Recent clinical study proved that UDCA could reduce the risk of the recurrence of $\mathrm{PBC}$ in patients post liver transplantation. It strengthened the evidence of therapeutic use of UDCA for PBC. Furthermore, UDCA could be developed as a potential drug for other illnesses such as cancer, obesity, heart failure, neurodegenerative diseases and others. Nevertheless, further studies on the clinical trial are still lacking.

\section{Acknowledgement}

We would like to thank the LPDP, Ministry of Finance, Republic of Indonesia for financial support of the study with the contract number 201807110213080

\section{Conflict of Interest}

The authors declare that they have no conflict of interest.

\section{References}

Abdulrab S, Al-Maweri S, Halboub E. 2020. Ursodeoxycholic acid as a candidate therapeutic to alleviate and/or prevent COVID-19-associated cytokine storm. Med Hypotheses 143: 109897. doi: 10.1016/j.mehy.2020.109897

Andersson, S, Davis DL, Dahlbäck H, Jörnvall H, Russell DW. 1989. Cloning, structure, and expression of the mitochondrial cytochrome P-450 sterol 26-hydroxylase, a bile acid biosynthetic enzyme. J Biol Chem 264(14): 8222-9

Antonenkov VD, van Veldhoven PP, Waelkens E, Mannaerts GP. 1999. Comparison of the stability and substrate specificity of purified peroxisomal 3-oxoacyl-CoA thiolases A and B from rat liver. Biochim Biophys Acta 1437(2): 136-41. doi: 10.1016/s1388-1981(99)00003-7

Beuers U, Trauner M, Jansen P, and Poupon R. 2015. New paradigms in the treatment of hepatic cholestasis: from UDCA to FXR, PXR and beyond. J Hepatol 62(1): S25-37. doi: 10.1016/j.jhep.2015.02.023

Björkhem I, Andersson O, Diczfalusy U, Sevastik B, Xiu R-J, Duan C, Lund E. 1994. Atherosclerosis and sterol 27-hydroxylase: evidence for a role of this enzyme in elimination of cholesterol from human macrophages. Proceedings of the National Academy of Sciences 91(18): 8592-6. doi: 10.1073/pnas.91.18.8592

Buchmann MS, Kvittingen EA, Nazer H, Gunasekaran T, Clayton PT, Sjövall J, and Björkhem I. 1990. Lack of 3 beta-hydroxy-delta 5-C27-steroid dehydrogenase/isomerase in fibroblasts from a child with urinary excretion of 3 beta-hydroxy-delta 5-bile acids. A new inborn error of metabolism. J Clin Invest 86(6): 2034-7. doi: 10.1172/JCI114939

Chen Y-S, Liu H-M, Lee T-Y. 2019. Ursodeoxycholic acid regulates hepatic energy homeostasis and white adipose tissue macrophages polarization in leptin-deficiency obese mice. Cells 8(3): 1-24. doi: 10.3390/cells8030253

Chiang JY. 1998. Regulation of bile acid synthesis. Front Biosci 3(4): 176 93. doi: $10.2741 / \mathrm{A} 273$

Chiang JYL. 2004. Regulation of bile acid synthesis: pathways, nuclear receptors, and mechanisms. $J$ Hepatol 40(3): 539-51. doi: 10.1016/j.jhep.2003.11.006

Chun HS, and Low WC. 2012. Ursodeoxycholic acid suppresses mitochondria-dependent programmed cell death induced by sodium nitroprusside in SH-SY5Y cells. Toxicology 292(2-3): 105-12. doi: 10.1016/j.tox.2011.11.020

Chung J, An SH, Kang SW, Kwon K. 2016. Ursodeoxycholic acid (UDCA) exerts anti-atherogenic effects by inhibiting RAGE signaling in diabetic atherosclerosis. PloS One 11(1): 1-18. doi: 10.1371/journal.pone.0147839

Clayton PT, Mills KA, Johnson AW, Barabino A, Marazzi MG. 1996. Delta 43-oxosteroid 5 beta-reductase deficiency: failure of ursodeoxycholic acid treatment and response to chenodeoxycholic acid plus cholic acid. Gut 38(4): 623-8. doi: 10.1136/gut.38.4.623

Colombo C, Battezzati PM, Podda M, Bettinardi N, and Giunta A. 1996. Ursodeoxycholic acid for liver disease associated with cystic fibrosis: A double- blind multicenter trial. Hepatology 23(6): 1484-90. doi: 10.1002/hep.510230627

Corpechot $\mathrm{C}$, Chazouillères $\mathrm{O}$, Belnou $\mathrm{P}$, Montano-Loza AJ, Mason A, Ebadi M, Eurich D, Chopra S, Jacob D, Schramm C. 2020. Long-term impact of preventive UDCA therapy after transplantation for primary biliary cholangitis. J Hepatol73(3): 559-65. doi: 10.1016/j.jhep.2020.03.043

Eggert T, Bakonyi D, Hummel W. 2014. Enzymatic routes for the synthesis of ursodeoxycholic acid. Biotechnol 191: 11-21. doi: 10.1016/j.jbiotec.2014.08.006

Elfahmi, Chahyadi A. 2020. The diversity of ursodeoxycholic acid precursors from bile waste of commercially available fishes, poultry and livestock in Indonesia. Braz J Pharm Sci 56: e18094. doi: 10.1590/s2175979020200001181094

Fang L, Zhou Y, Cao H, Wen P, Jiang L, He W, Dai C, Yang J. 2013. Autophagy attenuates diabetic glomerular damage through protection of hyperglycemia-induced podocyte injury. PloS One 8(4): 1-14. doi: 10.1371/journal.pone.0060546

Feng Y, Siu K, Wang N, Ng K-M, Tsao S-W, Nagamatsu T, Tong Y. 2009. Bear bile: dilemma of traditional medicinal use and animal protection. $J$ Ethnobiol Ethnomed 5(1): 1-9. doi: 10.1186/1746-4269-5-2

Ferdinandusse S, Houten, SM. 2006. Peroxisomes and bile acid biosynthesis. Biochim Biophys Acta Mol Cell Res 1763(12): 1427-40. doi: 10.1016/j.bbamcr.2006.09.001

Goossens J-F, Bailly, C. 2019. Ursodeoxycholic acid and cancer: From chemoprevention to chemotherapy. Pharmacol Ther 203: 1-13. doi: 10.1016/j.pharmthera.2019.107396

Hagey LR, Crombie DL, Espinosa E, Carey MC, Igimi H, Hofmann AF. 1993. Ursodeoxycholic acid in the Ursidae: biliary bile acids of bears, pandas, and related carnivores. J Lipid Res 34(11): 1911-7.

Hanafi NI, Kadir S, Mohamed AS, Noor J, Osman NJ, Siran R, Rahim S, and Hasani N. 2017. Ursodeoxycholic acid regulates caspase-9 and ros production in protecting cardiomyocytes against hypoxia. $J$ Teknol 79(2): 89-96. doi: 10.11113/jt.v79.9801

Hofmann AF, Hagey LR. 2014. Key discoveries in bile acid chemistry and biology and their clinical applications: history of the last eight decades. J Lipid Res 55(8): 1553-95. doi: 10.1194/jlr.R049437

Ibrahim E, Diakonov I, Arunthavarajah D, Swift T, Goodwin M, McIlvride S, Nikolova V, Williamson C, Gorelik J. 2018. Bile acids and their respective conjugates elicit different responses in neonatal cardiomyocytes: role of Gi protein, muscarinic receptors and TGR5. $S \mathrm{ci}$ Rep 8(1): 7110. doi: 10.1038/s41598-018-25569-4

Ishizaki K, Imada T, Tsurufuji M. 2005. Hepatoprotective bile acid 'ursodeoxycholic acid (UDCA)': Property and difference as bile acids. Hepatol Res 33(2): 174-7. doi: 10.1016/j.hepres.2005.09.029

Kase BF, Björkhem I. 1989. Peroxisomal bile acid-CoA:amino-acid Nacyltransferase in rat liver. J Biol Chem 264(16): 9220-3.

Keene CD, Rodrigues CM, Eich T, Linehan-Stieers C, Abt A, Kren BT, Steer CJ, Low WC. 2001. A bile acid protects against motor and cognitive deficits and reduces striatal degeneration in the 3-nitropropionic acid model of Huntington's disease. Exp Neurol 171(2): 351-60. doi: 10.1006/exnr.2001.7755

Kim SH, Chun HJ, Choi HS, Kim ES, Keum B, Seo YS, Jeen YT, Lee HS, Um $\mathrm{SH}$, Kim CD. 2018. Ursodeoxycholic acid attenuates 5-fluorouracilinduced mucositis in a rat model. Oncol Lett 16(2): 2585-90. doi: 10.3892/ol.2018.8893

Kim YJ, Jeong SH, Kim E-K, Kim EJ, Cho JH. 2017. Ursodeoxycholic acid suppresses epithelial-mesenchymal transition and cancer stem cell formation by reducing the levels of peroxiredoxin II and reactive oxygen species in pancreatic cancer cells. Oncol Rep 38(6): 3632-8. doi: 10.3892/or.2017.6045

Kohno H, Suzuki R, Yasui Y, Miyamoto S, Wakabayashi K, Tanaka T. 2007. Ursodeoxycholic acid versus sulfasalazine in colitis-related colon carcinogenesis in mice. Clin Cancer Res 13(8): 2519-25. doi: 10.1158/1078-0432.CCR-06-2727

Kuhajda K, Kandrac J, Kevresan S, Mikov M, Fawcett JP. 2006. Structure and origin of bile acids: an overview. Eur J Drug Metab Pharmacokinet 31(3): 135-43. doi: 10.1007/BF03190710

Lazaridis KN, Gores GJ, Lindor KD. 2001. Ursodeoxycholic acid 'Mechanisms of action and clinical use in hepatobiliary disorders'. $J$ Hepatol 35(1): 134-46. doi: 10.1016/s0168-8278(01)00092-7

Lee SH, Jang DK, Yoo M-W, Hwang S-H, Ryu S-Y, Kwon OK, Hur H, Yoon HM, Eom BW, Ahn HS, Son T, Song KY, Lee HH, Choi MG, An JY, Lee SI, Lee KH, Ahn S, Park YS, Park DJ. 2020. Efficacy and safety of ursodeoxycholic acid for the prevention of gallstone formation after gastrectomy in patients with gastric cancer: The PEGASUS-D randomized clinical trial. JAMA Surg 155(8): 703-11. doi: 10.1001/jamasurg.2020.1501

Lee WY, Han SH, Cho TS, Yoo YH, Lee SM. 1999. Effect of ursodeoxycholic acid on ischemia/reperfusion injury in isolated rat heart. Arch Pharmacal Res 22(5): 479-84. doi: 10.1007/BF02979156 
Li-Hawkins J, Lund, EG, Turley SD, Russell DW. 2000. Disruption of the oxysterol 7alpha-hydroxylase gene in mice. The Journal of Biological Chemistry 275(22): 16536-42. doi: 10.1074/jbc.M001811200

Li-Hawkins J, Lund EG, Bronson AD, Russell DW. 2000. Expression cloning of an oxysterol $7 \alpha$-hydroxylase selective for 24-hydroxycholesterol. $J$ Biol Chem 275(22): 16543-9. doi: 10.1074/jbc.M001810200

Lund EG, Guileyardo JM, Russell DW. 1999. cDNA cloning of cholesterol 24hydroxylase, a mediator of cholesterol homeostasis in the brain. Proceedings of the National Academy of Sciences of the United States of America 96(13): 7238-43. doi: 10.1073/pnas.96.13.7238

Mazzella G, Rizzo N, Azzaroli F, Simoni P, Bovicelli L, Miracolo A., Simonazzi G, Colecchia A, Nigro G, Mwangemi C, Festi D, Roda E. 2001. Ursodeoxycholic acid administration in patients with cholestasis of pregnancy: effects on primary bile acids in babies and mothers. Hepatology 33(3): 504-8. doi: 10.1053/jhep.2001.22647

Mima S, Sekiya C, Kanagawa H, Uchida T. 1994. Ursodeoxycholic acid (UDCA) therapy for autoimmune hepatitis. Int Hepatol Comm 2(4): 207-12. doi: 10.1016/0928-4346(94)90072-8

Miragoli M, Kadir SHSA, Sheppard MN, Salvarani N, Virta M, Wells S, Lab MJ, Nikolaev VO, Moshkov A, Hague WM, Rohr S, Williamson C, Gorelik J. 2011. A protective antiarrhythmic role of ursodeoxycholic acid in an in vitro rat model of the cholestatic fetal heart. Hepatology 54(4): 1282-92. doi: 10.1002/hep.24492

Norlin M, Wikvall K. 2007. Enzymes in the conversion of cholesterol into bile acids. Current Molecular Medicine 7(2): 199-218. doi: $10.2174 / 156652407780059168$

Noshiro M, Nishimoto M, Morohashi K, Okuda K. 1989. Molecular cloning of cDNA for cholesterol $7 \alpha$-hydroxylase from rat liver microsomes: nucleotide sequence and expression. FEBS Lett 257(1): 97-100. doi: 10.1016/0014-5793(89)81795-8

Park IH, Kim MK, Kim SU. 2008. Ursodeoxycholic acid prevents apoptosis of mouse sensory neurons induced by cisplatin by reducing p53 accumulation. Biochem Biophys Res Commun 377(4): 1025-30. doi: 10.1016/j.bbrc.2008.06.014

Pawlowski JE, Huizinga M, Penning TM. 1991. Cloning and sequencing of the cDNA for rat liver 3 alpha-hydroxysteroid/dihydrodiol dehydrogenase. $J$ Biol Chem 266(14): 8820-5.

Poupon R, Poupon RE. 1995. Ursodeoxycholic acid therapy of chronic cholestatic conditions in adults and children. Pharmacol Ther 66(1): 115. doi: 10.1016/0163-7258(94)00073-C

Prydz K, Kase BF, Björkhem I, Pedersen JI. 1988. Subcellular localization of 3 alpha, 7 alpha-dihydroxy- and 3 alpha,7 alpha,12 alpha-trihydroxy-5 beta-cholestanoyl-coenzyme A ligase(s) in rat liver. J Lipid Res 29(8): 997-1004.

Reiss AB, Martin KO, Javitt NB, Martin DW, Grossi EA, Galloway AC. 1994. Sterol 27-hydroxylase: High levels of activity in vascular endothelium. $J$ Lipid Res 35(6): 1026-30.

Ros E, Navarro S, Bru C, Gilabert R, Bianchi L, Bruguera M. 1993. Ursodeoxycholic acid treatment of primary hepatolithiasis in Caroli's syndrome. Lancet 342(8868): 404-6. doi: 10.1016/01406736(93)92817-d

Russell DW. 2003. The enzymes, regulation, and genetics of bile acid synthesis. Annu Rev Biochem 72(1): 137-74. doi: 10.1146/annurev.biochem.72.121801.161712

Šarenac TM, Mikov M. 2018. Bile acid synthesis: from nature to the chemical modification and synthesis and their applications as drugs and nutrients. Front Pharmacol 9: 939. doi: 10.3389/fphar.2018.00939

Šarenac TM, Mikov MM. 2017. Biosynthesis and biotransformation of bile acids. Hosp Pharm 4(1): 469-85. doi: 10.5937/hpimj1701469S

Schmitz W, Fingerhut R, Conzelmann E. 1994. Purification and properties of an alpha-methylacyl-CoA racemase from rat liver. Eur $J$ Biochem 222(2): 313-23. doi: 10.1111/j.1432-1033.1994.tb18870.x

Schwarz M, Lund EG, Lathe R, Björkhem I, Russell DW. 1997. Identification and characterization of a mouse oxysterol 7alpha-hydroxylase cDNA. $J$ Biol Chem 272(38): 23995-4001. doi: 10.1074/jbc.272.38.23995
Schwarz M, Wright AC, Davis DL, Nazer H, Björkhem I, Russell DW. 2000 The bile acid synthetic gene 3beta-hydroxy-Delta(5)-C(27)-steroid oxidoreductase is mutated in progressive intrahepatic cholestasis. $J$ Clin Invest 106(9): 1175-84. doi: 10.1172/JCI10902

Schwarz M, Lund EG, Setchell KDR, Kayden HJ, Zerwekh JE, Björkhem I, Herz J, Russell DW. 1996. Disruption of cholesterol $7 \alpha$-hydroxylase gene in mice: II. Bile acid deficiency is overcome by induction of oxysterol $7 \alpha$-hydroxylase. $J$ Biol Chem 271(30): 18024-31. doi: $10.1074 / \mathrm{jbc} .271 .30 .18024$

Setchell KD, Suchy FJ, Welsh MB, Zimmer-Nechemias L, Heubi J, Balistreri WF. 1988. Delta 4-3-oxosteroid 5 beta-reductase deficiency described in identical twins with neonatal hepatitis. A new inborn error in bile acid synthesis. J Clin Invest 82(6): 2148-57. doi: 10.1172/JCI113837

Shah SA, Looby E, Volkov Y, Long A, Kelleher D. 2005. Ursodeoxycholic acid inhibits translocation of protein kinase $\mathrm{C}$ in human colonic cancer cell lines. Eur J Cancer 41 (14): 2160-9. doi: 10.1016/j.ejca.2005.06.015

Shefer S, Cheng FW, Dayal B, Hauser S, Tint GS, Salen G, Mosbach EH. 1976 A 25-hydroxylation pathway of cholic acid biosynthesis in man and rat. J Clin Invest 57(4): 897-903. doi: 10.1172/JCI108366

Sinisalo J, Vanhanen H, Pajunen P, Vapaatalo H, Nieminen MS. 1999. Ursodeoxycholic acid and endothelial-dependent, nitric oxideindependent vasodilatation of forearm resistance arteries in patients with coronary heart disease. Br J Clin Pharmacol 47(6): 661-5. doi: 10.1046/j.1365-2125.1999.00940.x

Suzuki Y, Jiang LL, Souri M, Miyazawa S, Fukuda S, Zhang Z, Une M, Shimozawa N, Kondo N, Orii T, Hashimoto T. 1997. D-3-hydroxyacylCoA dehydratase/D-3-hydroxyacyl-CoA dehydrogenase bifunctional protein deficiency: a newly identified peroxisomal disorder. Am J Hum Genet 61(5): 1153-62. doi: 10.1086/301599

Takano S, Ito Y, Yokosuka O, Ohto M, Uchiumi K, Hirota K, Omata M. 1994. A multicenter randomized controlled dose study of ursodeoxycholic acid for chronic hepatitis C. Hepatology 20(3): 558-64.

Tonin F, Arends IWCE. 2018. Latest development in the synthesis of ursodeoxycholic acid (UDCA): A critical review. Beilstein J Org Chem 14(1): 470-83. doi: 10.3762/bjoc.14.33

Usui E, Noshiro M, Ohyama Y, Okuda K. 1990. Unique property of liver mitochondrial P450 to catalyze the two physiologically important reactions involved in both cholesterol catabolism and vitamin D activation. FEBS Lett 274(1-2): 175-7. doi: 10.1016/00145793(90)81357-t

Van Veldhoven PP, Vanhove G, Vanhoutte F, Dacremont G, Parmentier G, Eyssen HJ, Mannaerts GP. 1991. Identification and purification of a peroxisomal branched chain fatty acyl-CoA oxidase. $J$ Biol Chem 266(36): 24676-83.

Vaz FM, Ferdinandusse S. 2017. Bile acid analysis in human disorders of bile acid biosynthesis. Mol Aspects Med 56: 10-24. doi: 10.1016/j.mam.2017.03.003

Vlahcevic ZR, Pandak WM, Stravitz RT. 1999. Regulation of bile acid biosynthesis. Gastroenterol Clin North Am 28(1): 1-25. doi: 10.1016/s0889-8553(05)70041-8

Volkman J. 2003. Sterols in microorganisms. Appl Microbiol Biotechnol 60(5): 495-506. doi: 10.1007/s00253-002-1172-8

Wang J-Y, Wu, S.D. 2017. Ursodeoxycholic acid for the treatment of liver diseases. Liver Pathophysiology: 767-79. Elsevier. doi: 10.1016/b9780-12-804274-8.00055-2

Wang J, Gu X-Z, He L-M, Li C-C, Qiu W-W. 2020. Synthesis of ursodeoxycholic acid from plant-source (20S)-21-hydroxy-20methylpregn-4-en-3-one. Steroids 157: 108600. doi: $10.1016 /$ j.steroids. 2020.108600

Wu P, Zhao J, Guo Y, Yu Y, Wu X, Xiao H. 2020. Ursodeoxycholic acid alleviates nonalcoholic fatty liver disease by inhibiting apoptosis and improving autophagy via activating AMPK. Biochem Biophys Res Commun 529(3): 834-8. doi: 10.1016/j.bbrc.2020.05.128 